\title{
GirlsRead! Zambia: DREAMS Innovation Challenge
}

Population Council

Follow this and additional works at: https://knowledgecommons.popcouncil.org/departments_sbsr-pgy

Part of the Family, Life Course, and Society Commons, and the Gender Equity in Education Commons How does access to this work benefit you? Let us know!

\section{Recommended Citation}

"GirlsRead! Zambia: DREAMS Innovation Challenge," brief. New York: Population Council, 2018. 
000

$\because \cdots 0,0$

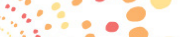

DREAMS

WORKING TOGETHER FOR

AN AIDS-FREE

FOR

\section{GirlsRead! Zambia: DREAMS Innovation Challenge}

\section{The Issue}

Schooling is vital not just for education outcomes, but evidence suggests that female education, particularly secondary school, decreases HIV risk. An analysis that identified the causal effect of secondary schooling on HIV infection in Botswana found that each additional year of secondary schooling reduced the risk of HIV by nearly 12 percentage points among women (DeNeve et al. 2015). Yet secondary school remains out of reach for many Zambian girls, and learning outcomes are poor. Indeed, among 15 countries in the Southern and Eastern Africa region, Zambian Grade 6 students scored the lowest on reading, with over two-thirds reading below a minimally acceptable level. One reason for the poor learning outcomes is the chronic lack of books.

\section{GirlsRead!}

GirlsRead! Zambia uses e-reader technology, girls' groups, and community engagement to improve girls' literacy and agency, and through these pathways, contributes to a reduction in HIV risk. A collaboration between DREAMS Innovation Challenge [which is funded by the President's Emergency Plan for AIDS Relief (PEPFAR)], the Zambian Ministry of General Education (MoGE), the Population Council, Worldreader, and the Forum for African Women Educationalists of Zambia (FAWEZA), GirlsRead! was implemented with Grade 7 girls in three sites in Zambia: Lusaka, Chingola, and Ndola. To address the underlying factors that put girls at risk for HIV the program combined:

- $\quad$ safe spaces for girls where mentors (one community mentor and one teacher mentor) facilitate an empowerment-based life-skills curriculum that covers topics such as gender equality and HIV prevention;

- $\quad$ e-readers that girls keep for the duration of the program with $\approx 100$ books of varying reading

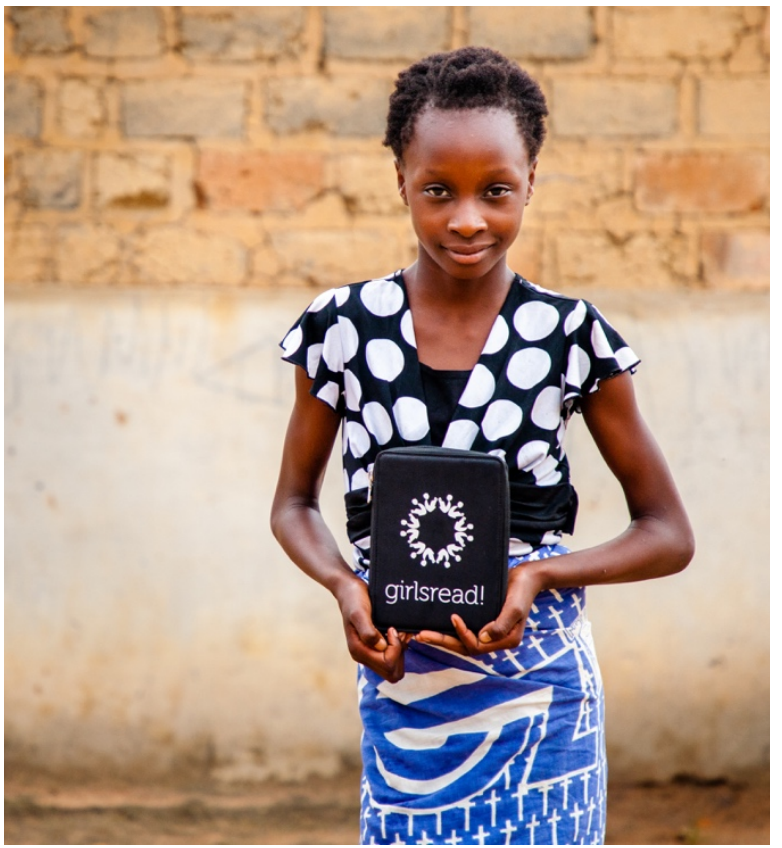

levels primarily written by African authors, with engaging content including alternative views of gender roles; and

- community engagement to bolster learning outcomes, promote gender equality, and reduce the likelihood that girls will leave school early.

Girls could charge e-readers at school using lowcost, locally-sourced, solar units, installed at each school.

\section{Evaluation}

GirlsRead! was assessed with careful monitoring and its impact evaluated with baseline and endline surveys and literacy assessments. Literacy was tested with the UWEZO assessment, a simple English diagnostic of progress in reading foundational skills

\section{Determined Resilient Empowered}

AlDS-Free

Mentored

Safe
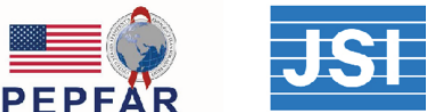

POPULATION COUNCIL Ideas. Evidence Impact.
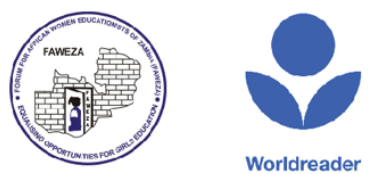

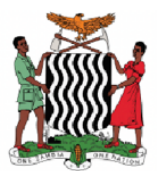




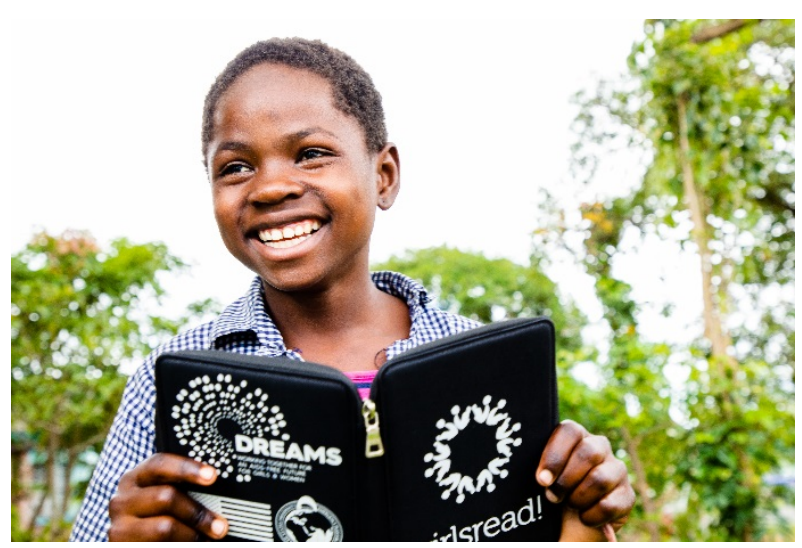

developed by the People's Action for Learning Network in East Africa; we calculated 3 outcomes: passed paragraph, passed story, and passed story questions. The survey assessed other indicators such as views on gender norms, self-efficacy, HIV knowledge, and violence.

Schools $(\mathrm{N}=36)$ were randomly assigned within each district to one of three arms:

Arm A: community engagement activities, girls' groups, and e-readers

Arm B: community engagement activities and girls' groups

Arm C: no (delayed) activities

To equalize exposure, girls in Arm B had study and homework time instead of e-reader time. Each intervention school (Arms A and B) had two girls' groups for a total of 48 groups with approximately 16 girls per group. Nineteen girls' group meetings were held for Arms A and B beginning in March 2017 and ending in September 2017. Additional sessions were held during school holidays for those interested.

A baseline survey was conducted in January-March 2017, prior to implementation of the girls' group sessions. The endline survey was conducted a year later from January to April 2018. The baseline sample consisted of 1299 girls; 1178 girls were interviewed at endline for a follow-up rate of $90.7 \%$. To measure impact, we examined whether there was a significant difference in endline indicators in the experimental arms (Arms A and B) compared to Arm $C$ (with no activities) controlling for baseline and other potentially confounding factors.

\section{Findings}

- Feasibility was demonstrated with only about $2.4 \%$ of e-readers lost, stolen, or broken.

- Attendance was high with over three-quarters of girls on average attending the 19 sessions.

- Preliminary analyses indicate significant impact on literacy both in intent to treat (ITT) analyseswhich includes all girls enrolled, regardless of whether or how much they participated-and treatment on the treated (TOT) analyses.

- For ITT results, compared to the control arm, passing the story at endline was 4.6 percentage points higher $(p<.1)$ in the e-reader arm and passing the two questions about the story was 6.4 percentage points higher $(p<.05)$ in the ereader arm.

- Among girls who attended $16+$ sessions (out of 19), these two literacy benchmarks at endline were $8(p<0.1)$ and $11(p<0.01)$ percentage points higher in the e-reader arm than in the control; among girls who attended 18+ sessions, the difference was $16(p<0.05)$ and $22(p<0.01)$ percentage points higher.

- Preliminary analyses of girls' gender attitudes show significantly more equitable attitudes for both ITT and TOT analyses when comparing GirlsRead! participants (Arms A and B) to girls in control schools at endline.

- Initial analyses of the General Self Efficacy scale do not show statistically significant differences between arms, though the effects of the program were in the hypothesized direction with experimental arm girls reporting greater selfefficacy at endline compared to girls in the control arm.

- In-depth interviews with e-reader arm girls indicate that most girls liked the e-reader stories; many mentioned that mentors were kind and supportive, that the reading was more enjoyable than school reading, and that they read more when they had the e-reader.

\section{Implications}

- E-readers are feasible in urban and rural African settings.

- $\quad$ Exposure to e-readers has the potential to enhance basic literacy skills among adolescent girls in a low-income setting.

- Attendance at empowerment-based safe spaces has the potential to significantly alter views on gender norms.

- Analyses of additional indicators continues, but in summary, it appears GirlsRead! has potential to decrease antecedent risk factors for HIV.

\section{References}

De Neve, J.W., Fink, G., Subramanian, S.V., Moyo, S. and Bor, J., 2015. Length of secondary schooling and risk of HIV infection in Botswana: evidence from a natural experiment. The Lancet Global Health, 3(8), pp. e470-e477. 